\title{
DAMPAK KLOROFLUOROKARBON TERHADAP LINGKUNGAN HIDUP
}

Oleh :

\author{
Sumingkrat *)
}

\begin{abstract}
As the first step in tackling environmental issues related to the protection of the ozone layer have been reviewed internationally. In Indonesia under the "Law concerning the Protection of the Ozone Layer by Means of Regulation on Specified Substance", regulations on the production and importation of controlled CFCs have been enforced since March 1991. The problems with CFCs are primarily environmental. CFCs destroy the stratospheric ozone layer that protects people from harmful ultraviolet rays from the sun. Already, holes and breaks in the ozone layer are apparent to scientists. Without the ozone layer's protective shild, skin cancer and eye damage are more likely among people, and the marine food chain could be profoundly disrupted. In addition, CFCs are responsible for about one-fifth of the greenhouse gases emitted into the atmosphere every year.
\end{abstract}

\section{PENDAHULUAN}

Lapisan ozon yang terdapat pada lapisan stratosfir pada ketinggian sekitar $20-50$ $\mathrm{km}$ diatas permukaan bumi, berfungsi melindungi bumi dari radiasi sinar ultraviolet matahari yang membahayakan. Meningkatnya konsentrasi gas-gas yang dibuat oleh manusia diantaranya CFC, Halon, CCL4, 1,1,1 trikloro-etan akan menyebabkan penipisan lapisan ozon. kiorofluorokarbon (CFCs) atau klorofluorokarbon telah dikembangkan pada tahun 1930 di General Motors untuk menggantikan bahan pendingin yang toksik dan korosif yang secara luas di-

*) Staf Peneliti

Balai Penelitian Pupuk dan Petrokimia

Balai Besar Industri Kimia. gunakan sebagai pendingin dalam lemari es pada saat itu. Thomas Midgley, pegawai dari General Motors itu telah menemukan "bahan kimia ajaib" mempunyai beberapa sifat yang dianggap dapat menggantikan semua bahan pendingin lainnya. Perdagangan CFCs tumbuh dengan cepat dan mempunyai peluang sebagai pendingin mantap dimasa datang. Pada awal tahun 1970, para ilmuwan telah mengingatkan bahwa kondisi lapisan ozon mulai menipis dan membahayakan. Semula Nitrogen Oksida yang berasal dari pesawat Supersonik diperkirakan sebagai penyebab utama terjadinya penipisan lapisan ozon, narnun pada tahun 1974 perhatian ilmuwan beralih pada bahan kimia yang dibuat manusia yaitu Klorofluoro karbon. CFCs menyebabkan menipisnya lapisan ozon di atmosfir, maka 
Akan menimbulkan terjadinya efek rumah kaca, dan radiasi ultraviolet-B yang berdampak negatif terhadap kesehatan manusia, biota, iklim dan lingkungan. Pada tahun 1986 lebih dari 300.000 ton CFCs telah diproduksi di Amerika Serikat tetapi kemudian disebut sebagai bahan kimia ajaib yang mempunyai sisi gelap. Sehubungan dengan hal ini, beberapa negara industri sudah membatasi peng-. gunaan $\mathrm{CFCs}$, seperti Du Pont salah satu industri terbesar di Amerika Serikat, setuju akan menghentikan semua produksi CFCs di tahun 2000. Bahan utama yang menjadi beban di atmosfir diantaranya adalah CFC-11 dan CFC-12, yang peningkatan penggunaannya secara global membawa konsekkuensi terhadap lingkungan dan kesehatan manusia. Sumber utama dari klorofluorokarbon adalah dari buangan industri, peralatan pendingin, pembuatan busa, pelarut, aerosol (hair spray, parfum) untuk sterilisasi dan lain sebagainya. Dalam perdagangan CFCs dikenal dengan nama Freon dan Halon. Karena penggunaannya yang terus meningkat dan dapat menimbulkan berbagai masalah, maka diupayakan berbagai cara untuk melindungi lingkungan, tanaman, biota laut dan manusia. Beberapa usaha telah dilakukan untuk mengurangi dampak tersebut antara lain "Helsinki Declaration", pada bulan April 1989 dan selanjutnya diselenggarakan "London Meeting", pada bulan Juli 1990 yang memutuskan penambahan bahan kimia yang diawasi sehingga menjadi : Kelompok CFC, Kelompok Halon, Kelompok Trikloroetan dan Kelompok Karbon-tetra-klorida. Halon adalah zat kimia yang sama dengan
CFCs yang diperkirakan produksinya dapat mencapai 20.000 ton/tahun, dan permintaan untuk bahan kimia ini berkembang terus. Halon 1301 berkemampuan untuk mengisi suatu ruang tertutup dan mematikan api tanpa membahayakan manusia dan merusak barang, oleh karena itu hal ini merupakan suatu dilema yang sulit. Dalam mencegah terjadinya bahaya akibat penipissan lapisan ozon telah dibuat perangkat hukum internasional, yaitu : "Vienna Convention" dan "Montreal Protocol" yaitu kerja sama dalam mengawasi bahan-bahan penyebab menipisnya lapisan ozon. Hal yang lebih penting adalah pemasyarakatan informasi mengenai keberadaan CFCs, daur ulang dan penghancuran CFCs dan halon serta menggunakan teknologi ramah ozon.

\section{SIFAT FISIK DAN KIMIA}

Klorofluorokarbon adalah bahan kimia yang berperan sebagai perusak ozon, merupakan bahan kimia sintetik berupa gas tidak beracin, murah, tidak berbau, tidak berwarna, tidak mudah terbakar dan tidak mudah bereaksi serta mempunyai kestabilan tinggi. Klorofluorokarbon di atmosfir menjadi senyawa klorin reakiif dalam jumiah besar apabila terkena radiasi sinar ultra violet di atas permukaan bumi. Pada saat itu CFCs akan terurai susunan kimia nya dan terjadi reaksi kimia sehingga melepaskan klorin yang akan menghancurkan ozon $\left(\mathrm{O}_{3}\right)$ menjadi oksigen $\left(\mathrm{O}_{2}\right)$ dengan reaksi pengikisan ozon yang dapat dilihat pada (gambar 1). Satu molekul CFCs dapat menghancurkan 10.000 sampai 100.000 molekul ozon, hal 
ini yang akan menyebabkan lapisan ozon berlubang. Sebelum adanya industrialisasi, tingkat klorin alamiah di atmosfir hanya mencapai 0,6 ppbv (ppbv = parts per billion by volume), terakhir diketahui bahwa senyawaan itu sudah mencapai 3,0 - 3,5 ppbv dan bertambah terus dengan cepat. CFCs dan Halon akan terus berada di atmosfir selama sekian dekade dalam beberapa hal dapat mencapai lebih dari 100 tahun. Bahkan bila kita ingin menghentikan emisi dan menghancurkan semua CFCs dan Halon yang tersisa, kita harus menunggu sampai akhir abad ke 21 agar senyawaan klorin di atmosfir menurun sampai ke tinggkat yang tidak merusak ozon. Setiap penipisan $10 \%$ dari lapisan ozon dapat menyebabkan kenaikan $20 \%$ radiasi ultra violet yang menimpa permukaan bumi dengan gelombanggelombang panjang. Akibatnya dapat menimbulkan dampak serius pada hampir semua kehidupan dan lingkungan di bumi. Senyawa klorin dan mungkin juga bromina yang stabil berubah menjadi bentuk yang sangat reaktif, zat-zat ini hanya memerlukan sinar matahari untuk mulai menyobek-nyobek molekul ozon, dengan daya rusak yang lebih cepat dan lebih awal dari teori yang diramalkan semula. Senyawa klorin reaktif yang tampak tidak berarti ini pada kenyataannya 100 kali lebih terkonsentrasi dibandingkan dengan bagian-bagian lain di stratosfir, dimana tidak terlihat adanya kerusakan ozon. Jenis Klorofluorokarbon yang paling merusak yaitu CFCs 11 dan CFCs 12, konsentrasinya meningkat lebih dari $85 \%$ antara tahun 1975 - 1980, dan jenis ini dapat bertahan dalam kurun waktu 65-110 tahun di atmosfir. Sedangkan halon merupakan bahan kimia dengan kelas yang sama dengan CFCs, bahan kimia ini mempunyai $3-10$ kali potensi menipis-kan lapisan ozon dibandingkan CFCs. Halon merupakan hidrokarbon yang mengandung bromin dan kadang-kadang juga klorin, keduanya akan merusak lapisan ozon. Halonkarbon ini, walaupun merusak ozon sepuluh kali lebih besar dari CFC, adalah sangat efektif untuk pemadam api karena zat ini tidak menghantarkan listrik, cepat menyebar, tidak meninggalkan residu dan tidak berbahaya bagi manusia. Klorofluorokarbon merupakan bahan kimia organik yang murni, hal ini dapat diketahui dari sifatnya ditandai dengan tekanan penguapan dan densitas yang tinggi. Selain itu sifatnya yang lain adalah mempunyai tegangan permukaan yang rendah serta larut dalam air. Tahan terhadap oksidasi dan mempunyai tingkat hidrolisis yang rendah. Gas-gas klorofluorokarbon dan fluorokarbon dikenal sebagai gas yang bersifat inert, maka dapat bertahan lama dan membentuk semacam lapisan gas yang menyebabkan efek rumah kaca ( green house effect ). Disebut efek rumah kaca karena berfungsi seperti kaca pada rumah kaca yang menangkap panasnya sinar matahari. Lapisan gas yang menyelimuti bumi ini menahan panas sinar matahari yang membuat suhu bumi meningkat terus. Klorofluorokarbon tahan terhadap oksidasi dan diketahui relatif stabil dari gangguan radikal hidroksil di dalam troposfir. Kelompok CFCs mempunyai tingkat hidrolisis yang rendah dibanding senyawa halogen yang lain, dan hidrolisisnya dipengaruhi oleh tekanan, 
suhu serta adanya material katalis seperti logam. Dapat melakukan fotolisis yaitu reaksi foto kimia, dimana atmosfir ozon mencegah seluruh sinar matahari yang panjang gelombangnya kurang dari 290 nm masuk kepermukaan bumi. Pada ketinggian dibawah $50 \mathrm{~km}$, bila panjang gelombang lebih besar dari $290 \mathrm{~nm}$ maka akan diserap oleh CFCs. CFC-11 dan CFC-12 tidak mengalami foto-dissosiasi di dalam troposfir dan tidak menyerap radiasi gelombang yang panjangnya lebih dari $200 \mathrm{~nm}$. Senyawa tersebut ternyata berdifusi di dalam stratosfir, tidak mengalami kerusakan oleh energi yang lebih tinggi atau gelombang sinar ultra violet yang lebih pendek. Hasil fotodissosiasi CFC-11 dan CFC-12 dilepaskan dua atom klorin dengan energi kecil untuk memecah ikatan C-CL dari ikatan C-F. Atom klorin yang dihasilkan dalam hal ini akan mengkatalisis dalam perusakan lapisan stratosfir lapisan ozon.

Gambar 1.

\section{REAKSI PENGIKISAN OZONE}

SINAR U.V.<smiles>CC(F)(F)Cl</smiles>

CI
$\mathrm{Cl}+\mathrm{O}_{3}$

$\mathrm{ClO}+\mathrm{O}$

$$
\mathrm{O}_{3}+\mathrm{O}
$$
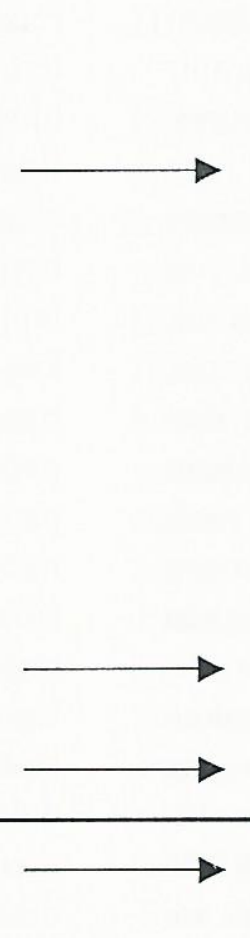

OZONE + ATOM OKSIGEN
ATOM Cl

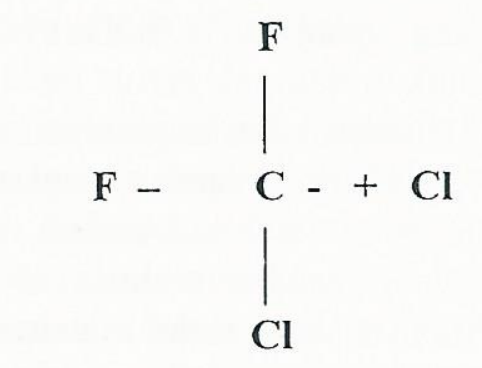

$$
\mathrm{ClO}+\mathrm{O}_{2}
$$

$\mathrm{Cl}+\mathrm{O}_{2}$

$2 \mathrm{O}_{2}$ 


\section{EFEK TERHADAP LINGKUNGAN}

Klorofluorokarbon secara perlahan-lahan dapat menyebabkan penipisan stratosfer ozon, dimana lapisan tipis dari atmosfir itu melindungi bumi dari bahayanya radiasi sinar ultra violet UV-B (Gambar 2). Berkurangnya ozon di stratosfer ini kemudian sangat diyakini sebagai penyebab berbagai kerusakan lingkungan yang luas di muka bumi. Maka secara otomatis sinar perusak ini dapat dengan leluasa memapar ke bumi hingga mengakibatkan beberapa dampak negatif (Gambar 3).

\section{Dampak terhadap Biota Darat}

Dampak radiasi UV-b terhadap kehidupan tumbuh-tumbuhan adalah dapat mengganggu kemampuan untuk menangkap energi sinar dalam proses fotosintetis. Penyerapan zat hara dan pertumbuhan tanaman tersebut juga terhambat sehingga mengganggu hasil panen. Jadi menipisnya lapisan ozon sangat mempengaruhi pertumibuhan dan produksi hutan. Beberapa tanaman rentan terhadap potensial peningkatan radiasi UV-B, antara lain golongan kacang-kacangan (leguminosae) seperti kapri, buncis dan bumbu-bumbuan. Efek dari perubahan tingkat radiasi UV-B terhadap kualitas tanaman yang diteliti menunjukkan bahwa protein dan kandungan minyak dari biji kedele mengalami penurunan lebih dari $10 \%$ bila terpaan radiasi ultra ungu pada simulasi penipisan ozon $25 \%$.

\section{Dampak Terhadap Biota Laut}

Peningkatan radiasi UV-B mengakibatkan
Rusaknya fitoplankton, zooplankton dan populasi plankton yang menjadi dasar dari jaringan makanan hewan laut. Hal ini mengakibatkan perubahan jumlah dan komposisi spisies sehingga akan mempengaruhi produksi ikan dan kerang secara keseluruhan. Keadaan ini secara langsung memberikan dampak terhadap penyediaan makanan juga mengganggu ekosistem dan kehidupan organisme laut.

\section{Dampak Terhadap Iklim}

Emisi klorofluorokarbon, selain menipiskan ozon distratosfer juga mempunyai andil pada terjadinya pemanasan global, karena klorofluorokarbon seperti $\mathrm{CO}_{2}$ termasuk dari gas-gas yang menyebabkan efek rumah kaca yang menghalangi panas keluar dari atmosfer. Setiap molekul CFC11 dan CFC-12 adalah $10.000 \times$ lebih efektif dalam menghalangi keluarnya panas dibandingkan 1 molekul $\mathrm{CO}_{2}$. Pada proses peningkatan suhu di atmosfer ini klorofluorokarbon menyumbang sekitar $15-20 \%$ dalam peningkatan suhu di atmosfer.

\section{PERLINDUNGAN DAN PENCEGAHAN}

Berdasarkan uraian sebelumnya dapat dinyatakan bahwa bahan-bahan kimia perusak ozon ini terutama berasal dari jenis klorofluorokarbon (CFC), yang digunakan dalam berbagai produk. Walaupun senyawa-senyawa tersebut bermanfaat untuk maksud lingkungan binaan tersebut, namun mengingat dampak dari perusakan lapisan ozon dalam lingkup kestabilan lingkungan global sangat meluas, maka telah disepakati oleh masyarakat dunia 
Gambar 2. Mekanisme Penipisan Lapisan Ozon

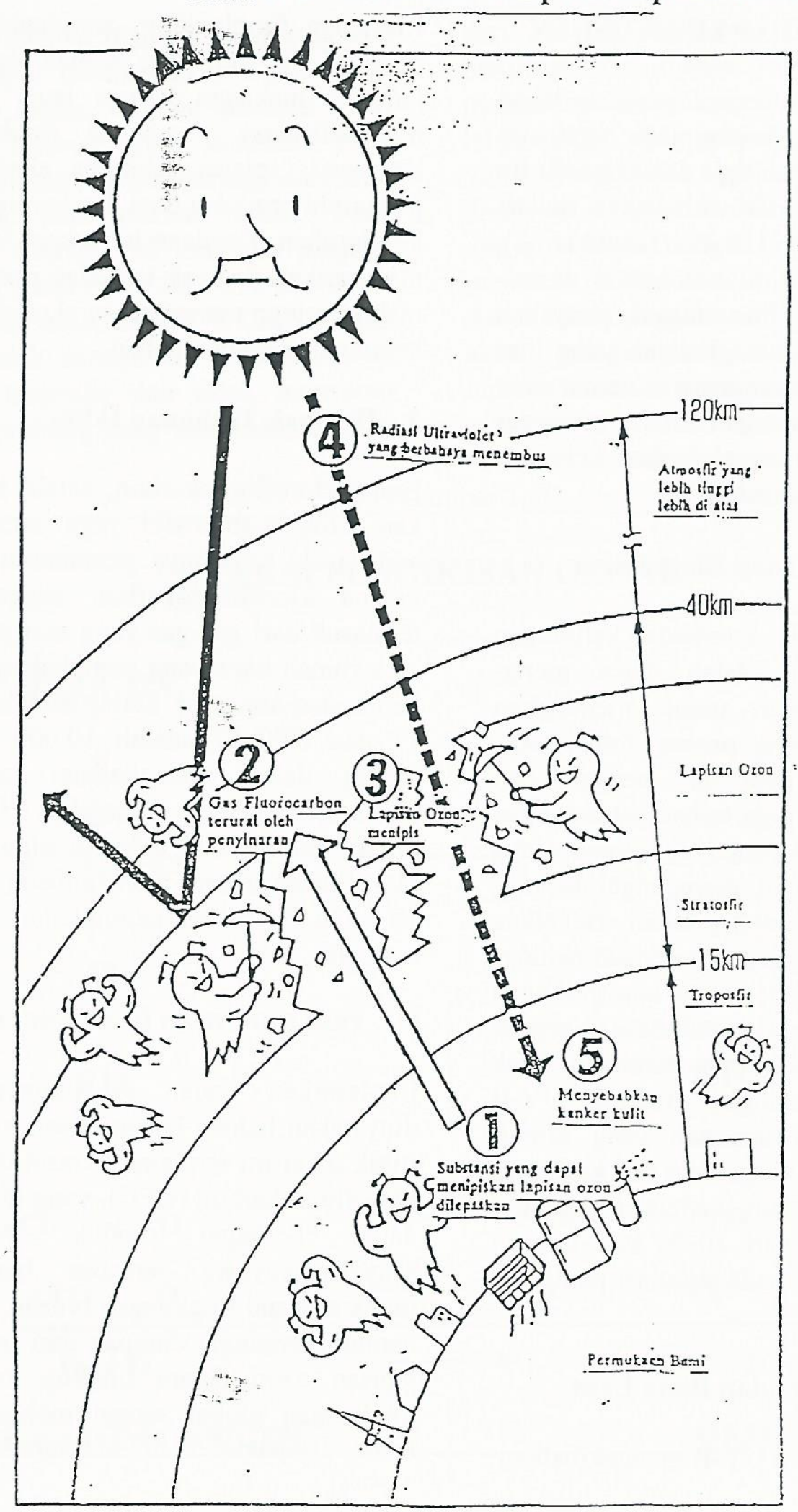


Gambar 3. Dampak Negatif Sinar Ultra Violet Terhadap Lingkungan
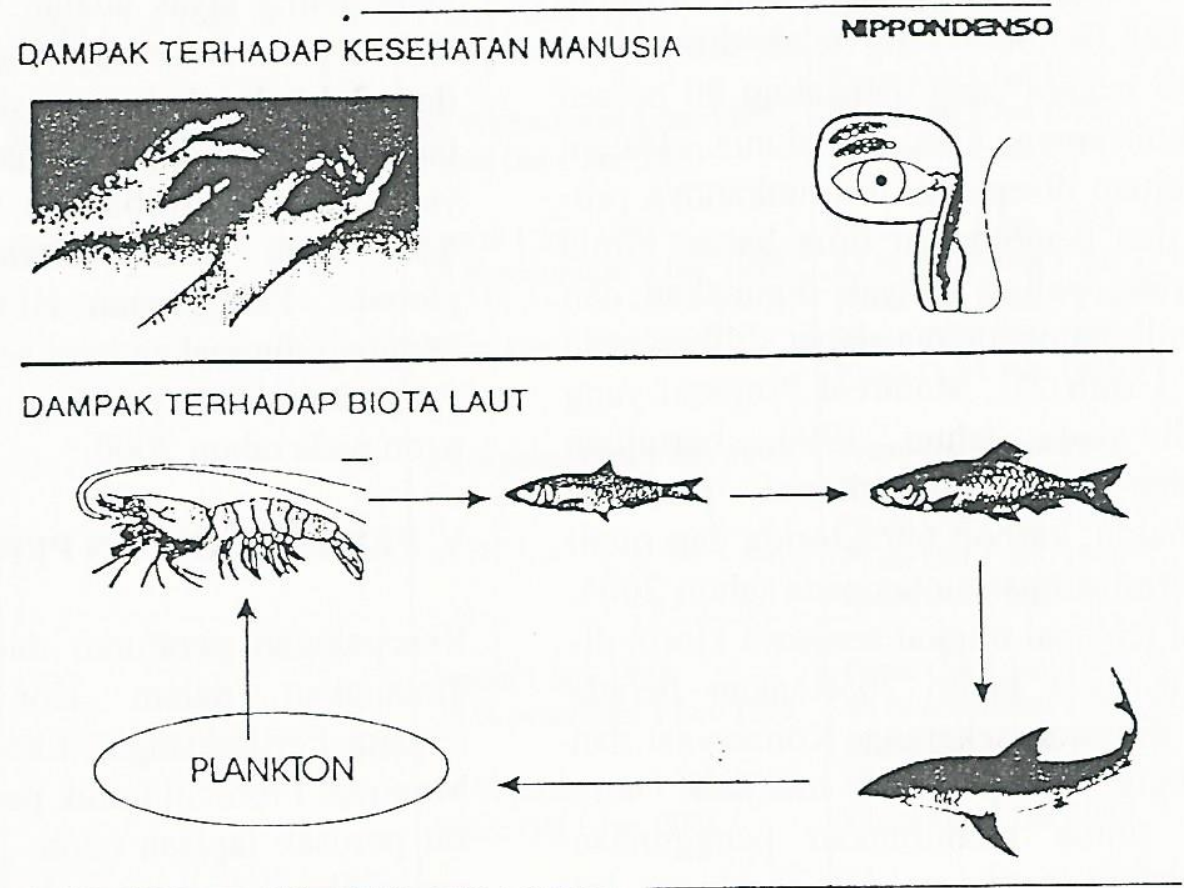

DAMPAK TERHADAP BIOTA DARAT

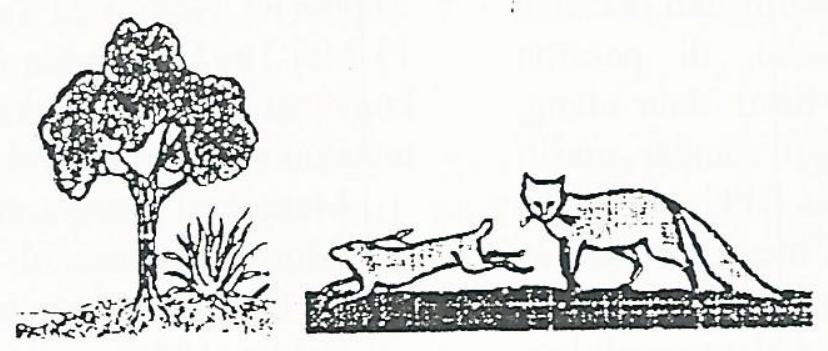


Bahwa senyawa tersebut harus dihapuskan penggunaannya dan dicarikan penggantinya yang bersahabat dengan lingkungan. Persetujuan di Montreal, Kanada pada tahun 1987 yang kemudian disebut Montreal Protocol yang telah diratifikasi oleh 36 negara yang mencakup 80 persen dari konsumen CFC di dunia. Dalam persetujuan disepakati diturunkannya produksi dan penggunaan lima bahan kimia CFC yang paling banyak digunakan dan tiga jenis halon utama dapat dilihat pada (tabel 1 dan 2). Montreal Protocol yang dirubah pada tahun 1990, bertujuan berangsur-angsur menghapus produksi $\mathrm{CFC}$, halon, karbon tetraklorida dan metil kloroform sampai tuntas pada tahun 2005. Bila ini tercapai tingkat senyawa klorin diatmosfir pada tahun 2050 akan berada sedikit dibawah sekarang. Konservasi dan daur-ulang tampaknya menjadi cara terbaik untuk menurunkan penggunaan CFCs dalam jangka pendek, meskipun ini masih sulit dilaksanakan. Hal ini disebabkan peraturan insentif dan masalah ekonomi kurang memadai, di pasaran belum mau menerima hasil daur-ulang, kemurnian dan spesifikasi standar masih menghendaki penggunaan $\mathrm{CFC}$ dan halon baru. Montreal Protocol mengakui bahwa menghentikan perusakan terhadap lapisan ozon dalam masalah global memerlukan pemecahan global, maka keahlian teknis harus dikembangkan terutama oleh negara kaya yang sampai sekarang menjadi pembuat dan pemakai utama dari CFC. Agar negara-negara berkembang dapat meninggalkan teknologi tua dan penyebab pencemaran dan langsung menggunakan teknologi baru yang aman bagi lingkungan
Diperlukan alih teknologi internasional, termasuk pelatihan teknis, insentif perdagangan, usaha patungan dan bantuan multi dan bilateral. Calon pengganti CFCs yang paling layak adalah HFC134a dapat dilihat pada informasi teknik (tabel 3 a dan 3 b) dan beberapa sifat dari bahanbahan tersebut dapat dilihat pada (tabel 3) yang tidak menyebabkan penipisan ozon dan tidak menyebabkan pemanasan global. Penggunaan HFC 134a secara bertahap digunakan bagi semua kendaraan yang memakai pendingin yang ramah ozon pada tahun 2000 .

\section{PERATURAN DAN PERUNDANGAN}

Kesepakatan peraturan dan perundangan dituangkan dalam Konvensi Vienna tentang Perlindusngan Lapisan Ozon dan Montreal Protocol untuk penghapusan zatzat perusak lapisan ozon. Indonesia telah meratifikasi konvensi Vienna Montreal Protocol yang terlaksana dengan adanya Kepres RI. Nomor 23 Tahun 1992 tanggal 13 Mei 1992. Dengan meratifikasi kedua konvensi tersebut maka Indonesia harus melakukan beberapa kebijaksanaan umum

1. Mengikuti persyaratan minimal dari Montreal Protocol bahwa konsumsi CFC masih dibawah 0,3 kg/kapita/tahun (1986).

2. Melakukan berbagai upaya tindak lanjut, termasuk peraturan perundangan, pemberian label pada produk yang mengandung $\mathrm{CFC}$ atau bebas CFCs.

3. Tidak memberikan ijin untuyk pendirian industri yang menghasilkan bahan perusak ozon seperti CFCs, HCFC, Halon dan Klorin Bromin. 
Tabel 1. Jadwal Pengurangan Produksi dan Konsumsi ODP

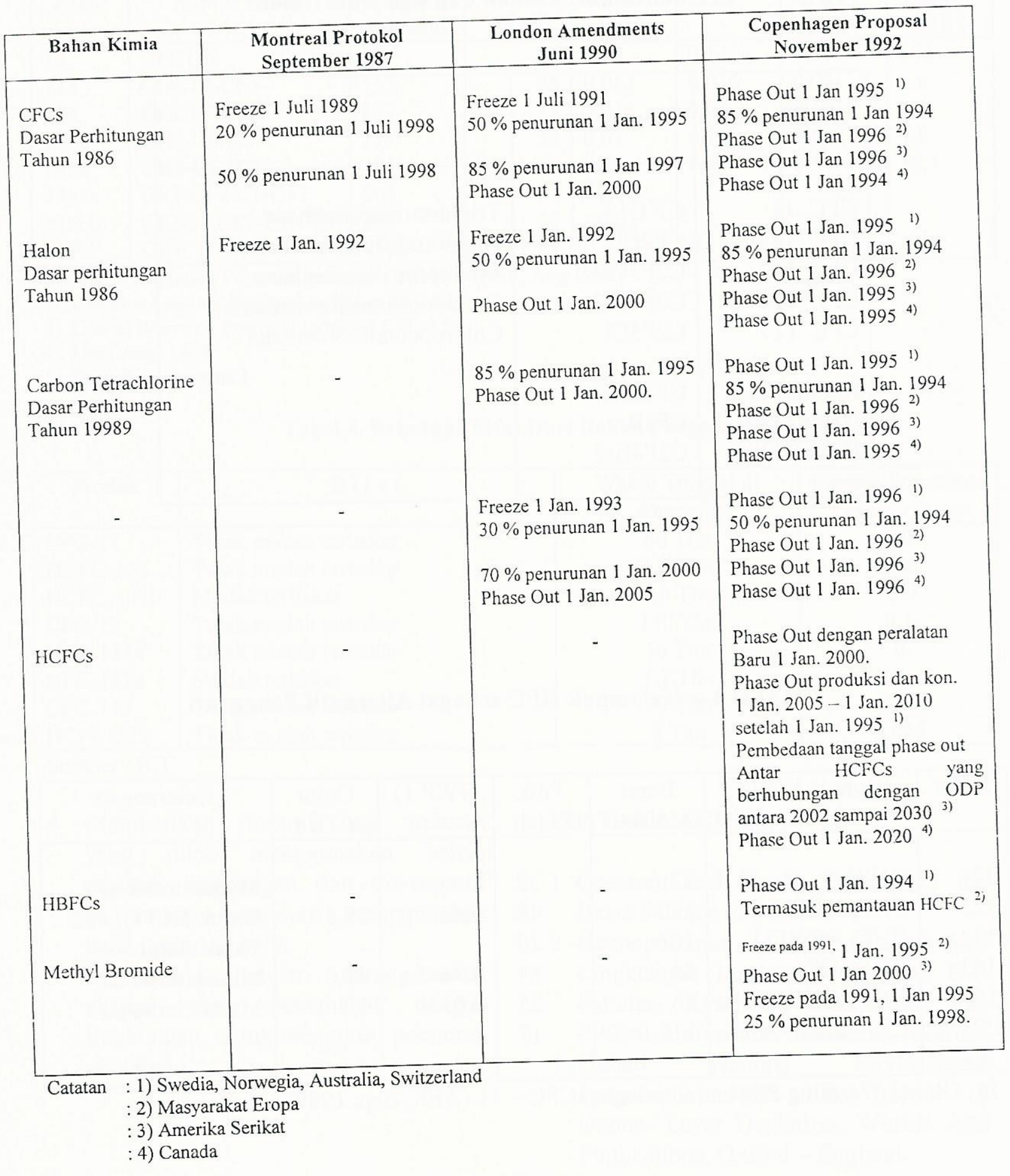

BULLETIN PENELITIAN, Agustus 1998,Vol.XX,No.2 
Tabel 2. Lima Jenis Bahan Kimia

Chlorofluorokarbon dan tiga jenis Halon

\begin{tabular}{|c|c|c|}
\hline Kode & Rumus Kimia & Uraian \\
\hline $\begin{array}{ll}\text { CFC } & 11 \\
\text { CFC } & 12 \\
\text { CFC } & 113 \\
\text { CFC } & 114 \\
\text { CFC } & 115 \\
\text { Halon } & 1211 \\
\text { Halon } & 1301 \\
\text { Halon } & 2402\end{array}$ & $\begin{array}{l}\mathrm{CF} \mathrm{C} 13 \\
\mathrm{CF} 2 \mathrm{Cl} 2 \\
\mathrm{C} 2 \mathrm{~F} 3 \mathrm{Cl} 3 \\
\mathrm{C} 2 \mathrm{~F} 4 \mathrm{Cl} 2 \\
\mathrm{C} 2 \mathrm{~F} 5 \mathrm{Cl} \\
\mathrm{CF} 2 \mathrm{BrCl} \\
\mathrm{CF} 3 \mathrm{Br} \\
\mathrm{C} 2 \mathrm{~F} 4 \mathrm{Br} 2\end{array}$ & $\begin{array}{l}\text { Trichlorofuoromethane } \\
\text { Dichlorodifluoromethane } \\
\text { Trichlorotrifluoroethane } \\
\text { Dichklorotetrafluoroethane } \\
\text { Chloropentafluoroethane }\end{array}$ \\
\hline
\end{tabular}

Tabel 3 a. Kelompok HFC sebagai Alternatif Pengganti

\begin{tabular}{|c|c|c|c|c|c|c|}
\hline Kode & Rumus Kimia & $\begin{array}{c}\text { Berat } \\
\text { Molekul }\end{array}$ & $\begin{array}{l}\text { Titik } \\
\text { Leleh }\end{array}$ & GWP 1) & $\begin{array}{l}\text { Umur } \\
(\mathrm{Th})\end{array}$ & Keterangan \\
\hline $\begin{array}{l}32 \\
125 \\
134 \mathrm{a} \\
143 \mathrm{a} \\
152 \mathrm{a} \\
227\end{array}$ & $\begin{array}{l}\mathrm{CH}_{2} \mathrm{~F}_{2} \\
\mathrm{CHF}_{2}-\mathrm{CF}_{3} \\
\mathrm{CHF}_{2}-\mathrm{CHF}_{2} \\
\mathrm{CH}_{3}-\mathrm{CF}_{3} \\
\mathrm{CH}_{3}-\mathrm{CHF}_{2} \\
\mathrm{CF}_{3}-\mathrm{CHF}-\mathrm{CH}_{3}\end{array}$ & $\begin{array}{l}32 \\
120 \\
102 \\
84 \\
66 \\
170\end{array}$ & $\begin{array}{l}-52 \\
-\quad 48 \\
-\quad 20 \\
-\quad 84 \\
-\quad 25 \\
-\quad 17\end{array}$ & $\begin{array}{l}- \\
0,65 \\
- \\
0,76 \\
0,033 \\
-\end{array}$ & $\begin{array}{l}- \\
28,1 \\
- \\
41,0 \\
1,7 \\
-\end{array}$ & $\begin{array}{l}\text { Mudah terbakar } \\
\text { Untuk HCFC - } 22 \\
\text { Tidak stabil } \\
\text { Mudah terbakar } \\
\text { Mudah terbakar } \\
\text { - }\end{array}$ \\
\hline
\end{tabular}

1) Global Warming Potyential terhadap CFC - 11 (AER, Sep. 1989) 
Tabel 3 b. Kelompok HCFC Alternatif Pengganti

\begin{tabular}{|l|l|l|r|l|l|l|l|}
\hline Kode & \multicolumn{1}{|c|}{ Rumus Kimia } & $\begin{array}{c}\text { Berat } \\
\text { Molekul }\end{array}$ & $\begin{array}{c}\text { Titik } \\
\text { Leleh }\end{array}$ & ODP & CLP $^{2)}$ & GWP $^{3)}$ & $\begin{array}{c}\text { Umur } \\
\text { (Th })\end{array}$ \\
\hline 22 & CFC1F2 & 87 & -41 & 0,04 & 0,14 & 0,37 & 153 \\
123 & CHC12-CF3 & 153 & 28 & 0,013 & 0,016 & 0,02 & 1,6 \\
124 & CHC1F-CF3 & 137 & -12 & 0,016 & 0,04 & 0,10 & 6,6 \\
$141 \mathrm{~b}$ & CH3-CC12F & 117 & 32 & 0,07 & 0,10 & 0,097 & 7,8 \\
$142 \mathrm{~b}$ & CH3-CC1F2 & 101 & -9 & 0,05 & 0,14 & 0,39 & 19,1 \\
$225 \mathrm{ca}$ & CF3-CF2-CHC12 & 203 & 51 & $<0,02$ & & & \\
$225 \mathrm{cb}$ & CF2C1-CF2-CHC12 & 203 & 56 & $<0,02$ & & & \\
PFP $^{5)}$ & CF3CF2OH & 150 & 81 & 0 & 0 & & \\
\hline
\end{tabular}

1). Ozone Depleting Potential terhadap CFC-11 (UNEP, Aug 1989)

2). Chlorine Loading Potential terhadap CFC-11

3). Global Warming Potential terhadap CFC-11

4). Unef Aug. 1989

5). Pentafluoropropanol

Tabel 4. Beberapa Sifat Dari Bahan Pengganti CFC

\begin{tabular}{|l|l|c|c|}
\hline \multicolumn{1}{|c|}{ Produk } & \multicolumn{1}{|c|}{ S i f a t } & $\begin{array}{c}\text { Waktu Tinggal di } \\
\text { Atmosfir }\end{array}$ & $\begin{array}{c}\text { Potensi Perusakan } \\
\text { Lapisan Ozon }\end{array}$ \\
\hline CFC-11 & Tidak mudah terbakar & $60 \mathrm{Thn}$ & 1,0 \\
HCFC-123 & Tidak mudah terbakar & $1,6 \mathrm{Thn}$ & 0,02 \\
HCFC-141b & Mudah terbakar & $8,0 \mathrm{Thn}$ & 0,11 \\
CFC-12 & Tidak mudah terbakar & $130 \mathrm{Thn}$ & 0,1 \\
HFC-134a & Tidak mudah terbakar & $16 \mathrm{Thn}$ & 0 \\
HFC-152a & Mudah terbakar & $1,7 \mathrm{Thn}$ & 0 \\
CFC-113 & Tidak mudah terbakar & $90 \mathrm{Thn}$ & 0,85 \\
HCFC-225 & Tidak mudah terbakar & 2 Thn & 0,025 \\
\hline
\end{tabular}

Sumber : ICl

4. Memberikan insentif bagi industri

PUSTAKA ACUAN. yang tidak menggunakan bahan perusak lingkungan dan dis-insentif bagi industri yang masih menggunakan bahan perusak ozon.

5. Mendorong industri barang-barang ekspor yang bersahabat dengan lingkungan, untuk mengikuti peraturan ekolabel.

1. Cassarett and Douls, Toxicology the Basic Science of Poisons.

2. Kusnoputranto,. H. 1996. Toksikologi Lingkungan Logam Toksik dan B-3 Fakultas Kesehatan Masyarakat dan PPSML Universitas Indonesia, Jakarta.

3. United Nations Environment Programme, 1992. The impact of Ozone- Layer Depletion, Worlds And Puplications, Oxford - England. 